\title{
FAKTOR - FAKTOR YANG BERHUBUNGAN DENGAN MINAT IBU DALAM PEMILIHAN ALAT KONTRASEPSI IUD
}

\author{
Yati Nur Indah Sari ${ }^{1}$, Urwatil Wusqa Abidin ${ }^{2}$, Sri Ningsih ${ }^{3}$ \\ ${ }^{1}$ Kampus Universitas Al Asyariah Mandar, Fakultas Kesehatan Masyarakat. D/a. Jl. Budi Utomo \\ No.2 Manding, Kecamatan Polewali, Kabupaten Polewali Mandar, Provinsi Sulawesi Barat, \\ Indonesia \\ E-mail: yatinurindah@gmail.com
}

\begin{abstract}
Abstrack
Family planning movement done to the $23 \mathrm{rd}$ in which there shall be welfare then family planning program is one of the most effective way to improving the survival of the family, health and maternal and child safety. The government policy on family planning leads to the long period contraceptives, Intra uterine device IUD is one of the long term contraception devices the most effective and safe. The study aimed to identify factors associated with maternal interest in an election of contraceptive IUD by using the method cross sectional analytic survey design. Included in this research was wus acceptors active 107 some respondents taken with purposive techniques of sampling. Instrument research using a questionnaire and data analyzed use chi-square test. The results of the analysis mother relationship with their respective interest in the election of a contraceptive device iud show the economic situation of significance $>0.05$ Obtained the $p=0.149$ significance $p=0.149$ for knowledge, value $p=0.009$ For support husband, value $p=0.132$ to private ownership management agency bpjs, value $p=0.440$ for the media. Factors that are not relating to interest mother in the contraceptives IUD Sidodadi urban village is knowledge, BPJS ownership, and media. It is expected that midwives to services provided the assist to socialize with BPJS IUD, myths, Effectiveness and side effects iud and educate to join the IUD BPJS get the service free. It is expected that husbands to as well as in the socialization for husband be able to support his wife to use IUD Keywords: knowledge, Husband support, BPJS, the media, IUD
\end{abstract}

\begin{abstract}
ABSTRAK
Gerakan keluarga berencana dilakukan untuk membangun keluarga yang sejahtera maka program KB merupakan salah satu cara yang paling efektif untuk meningkatkan ketahanan keluarga, kesehatan, serta keselamatan ibu dan anak. Kebijakan pemerintah tentang KB saat ini mengarah pada pemakaian metode kontrasepsi jangka panjang, Intra Uterine Device (IUD) adalah salah satu alat kontrasepsi jangka panjang yang paling efektif dan aman. Penelitian ini bertujuan untuk mengetahui faktor-faktor yang berhubungan dengan minat ibu dalam pemilihan alat kontrasepsi IUD dengan menggunakan metode survey analitik dengan rancangan Cross Sectional. Sampel dalam penelitian ini adalah WUS akseptor KB aktif sebanyak 107 responden yang diambil dengan teknik Purposive Sampling. Instrument penelitian menggunakan kuesioner dan data dianalisis menggunakan uji Chi-Square. Hasil analisis hubungan dengan minat ibu dalam pemilihan alat kontrasepsi IUD menunjukkan pada taraf signifikansi $>0,05$ diperoleh nilai signifikansi sebesar nilai $\mathrm{p}=0,149$ untuk pengetahuan, nilai $\mathrm{p}=0,009$ untuk dukungan suami, nilai $\mathrm{p}=0,132$ untuk kepemilikan BPJS, nilai $\mathrm{p}=0,440$ untuk media. Faktor-faktor yang tidak berhubungan dengan minat ibu dalam pemilihan alat kontrasepsi IUD di kelurahan sidodadi adalah pengetahuan, kepemilikan BPJS dan media. Diharapkan bidan untuk memeberikan sosialisasi terkait layanan IUD dengan BPJS, mitos-mitos, efektivitas dan efek samping IUD serta mengedukasi untuk bergabung dengan program BPJS mendapatkan layanan IUD gratis. Diharapkan suami ikut serta dalam sosialisasi agar suami dapat mendukung istrinya untuk menggunakan IUD.
\end{abstract}

Kata kunci : Pengetahuan, dukungan suami, BPJS, media, IUD, minat 


\section{PENDAHULUAN}

Laju pertumbuhan penduduk yang tidak dapat dikendalikan mengakibatkan banyak dampak terhadap penduduk yaitu menderita kekurangan makanan dan gizi sehingga mengakibatkan tingkat kesehatan memburuk, mempunyai pendidikan yang rendah, dan banyak penduduk yang pengangguran (BKKBN, 2015). Indonesia masih menduduki urutan ke empat dengan penduduk terbanyak di dunia setelah China, India dan Amerika (World Population Data Sheet, 2015). Berdasarkan data Profil Kesehatan Indonesia pada tahun 2017, Indonesia memiliki jumlah penduduk mencapai 261.890.872 jiwa.

Program yang dilakukan oleh pemerintah untuk mengurangi laju pertumbuhan penduduk dapat dilakukan dengan gerakan Keluarga Berencana dan pemakaian alat kontrasepsi secara sukarela kepada PUS. Gerakan keluarga berencana dilakukan untuk membangun keluarga yang sejahtera dalam rangka menciptakan sumber daya manusia yang optimal. Program KB merupakan salah satu cara yang paling efektif untuk meningkatkan ketahanan keluarga, kesehatan, dan keselamatan ibu, anak, serta perempuan (BKKBN, 2015).

Kebijakan pemerintah tentang $\mathrm{KB}$ saat ini mengarah pada pemakaian metode kontrasepsi jangka panjang (Balitbangkes, 2013). Intra Uterine Device (IUD) adalah salah satu alat kontrasepsi jangka panjang yang paling efektif dan aman dibandingkan alat kontrasepsi lainnya seperti pil. Alat kontrasepsi IUD sangat efektif untuk menekan angka kematian ibu dan mengendalikan laju pertumbuhan penduduk karena tingkat efektifitas penggunaan sampai 99,4\% dan IUD dapat digunakan untuk jangka waktu 3-5 tahun (jenis hormon) dan 510 tahun (jenis tembaga). Alat kontasepsi IUD dimasukkan kedalam rahim yang bentuknya bermacam- macam, terdiri dari plastik (polyethylene) (Handayani, 2010).

Data Profil Kesehatan Indonesia tahun 2016, menunjukan jumlah penduduk Sulawesi Barat terdiri dari 1.306.478 jiwa. Dengan jumlah keseluruhan PUS terdiri dari 216.025 jiwa, dan jumlah akseptor KB aktif 161.532 jiwa $(74,77 \%)$ yang menggunakan suntik $(41,23 \%)$, pil $(34,89 \%)$, kondom $(5,65 \%)$, implant (11,32\%), IUD (4,39\%), MOP $(0,42 \%)$, MOW (2,11\%). Sedangkan untuk akseptor KB baru 31.377 jiwa yang menggunakan suntik $(14,74 \%)$, pil $(8,69 \%)$, kondom $(0,59 \%)$, implant $(2,57 \%)$, IUD $(0,55 \%)$, MOP $(0,34 \%)$, MOW $(0,07 \%)$ (Kemenkes RI, 2016).

Eny Astuti (2018) mengungkapkan terdapat empat faktor yang mempengaruhi minat ibu untuk menggunakan kontrasepsi IUD yakni faktor pengetahuan, agama, ekonomi, dan budaya. Desitavani (2017) menyatakan bahwa ada hubungan antara pendidikan, pekerjaan, sosial ekonomi, budaya, tingkat pengetahuan dan dukungan suami dengan pemilihan alat kontrasepsi IUD, dan tidak ada hubungan antara umur dan paritas dengan pemilihan alat kontrasepsi IUD. Teori Health Belief Model (HBM) Lewin (1954) dalam Notoatmodjo (2008) mengungkapkan bahwa rendahnya minat MKJP dipengaruhi oleh persepsi individu mengenai ancaman dan pertimbangan untung rugi. Persepsi individu dipengaruhi faktor pemodifikasi yaitu usia, pendidikan, pengetahuan, jumlah anak, paparan sumber informasi dan kondisi ekonomi.

Profil Dinas Kesehatan Polewali Mandar Tahun 2015 jumlah penduduk Kabupaten Polewali Mandar yaitu 417.472 jiwa, dengan jumlah peserta KB aktif sebanyak 43.301, akseptor MKJP 3.087 
$(7,1 \%)$ dan non MKJP 40.214 (92,9\%). Merlis Simon (2018), mengungkapkan bahwa terdapat adanya pengaruh pemberian KIE terhadap penggunaan alat kontrasepsi IUD dan terdapat pengaruh dukungan suami terhadap terhadap penggunaan alat kontrasepsi IUD. Hadriah Oesman (2017), mengungkapkan bahwa Pemakaian kontrasepsi non MKJP masih tinggi. Pemanfaatan kartu BPJS kesehatan untuk pelayanan $\mathrm{KB}$ masih rendah, padahal pemanfaatan kartu BPJS kesehatan berpeluang hampir empat kali dapat mendorong pemakaian KB MKJP.

Kelurahan Sidodadi terletak di wilayah Kecamatan Wonomulyo Kabupaten Polewali Mandar dengan cakupan IUD yang cenderung rendah. Data internal BPS Sri Romdhati tahun 2015 mencatat data. Balai Keluarga Berencana Kecamatan Wonomulyo Kabupaten Polewali Mandar tahun 2017 untuk Kelurahan Sidodadi tercatat dari total PUS 1879 akseptor KB aktif sebanyak 1396, pengguna IUD 28 akseptor, implant 43 akseptor, MOW 45 akseptor, suntik 658 akseptor, pil 515 akseptor dari keseluruhan pasien KB. Atas dasar data tersebut maka penulis merasa perlu untuk mengetahui faktorfaktor yang berhubungan dengan minat ibu dalam pemilihan alat kontrasepsi IUD di Kelurahan Sidodadi Kecamatan Wonomulyo.

\section{BAHAN DAN METODE}

Jenis penelitian yang digunakan adalah survey analitik dengan rancangan cross sectional. Penelitian ini dilaksanakan di Kelurahan Sidodadi Kecamatan Wonomulyo, yang berlangsung selama 20 hari yakni mulai tanggal 20 Februari s/d 11 Maret. Responden terdiri atas 107 orang dengan kriteria inklusi WUS yang ber KB aktif dan kriteria eksklusi adalah yang bukan WUS dan tidak ber KB aktif yang diambil dengan teknik purposive sampling.Variabelvariabel dalam penelitian ini menggunakan skala data nominal, instrument penelitian menggunakan kuesioner dan data dianalisis menggunakan uji ChiSquare antara variabel dependen (minat menggunakan IUD) dan independen (pengetahuan, dukungan suami, kepemilikan BPJS, media), kemudian disajikan dalam bentuk tabel.

\section{HASIL}

Karakteristik responden meliputi umur, jumlah anak, jenis kontrasepsi, pendidikan istri, pendidikan suami, biaya KB dan BPJS.

\section{Analisis Univariat}

Tabel 1. Distribusi Karakteristik Responden di Kelurahan Sidodadi Kecamatan Wonomulyo

\begin{tabular}{lccc}
\hline & Karakteristik Responden & n & \% \\
\hline \multirow{3}{*}{ Umur } & $\leq 20$ Tahun & 7 & 6,6 \\
& $21-30$ Tahun & 36 & 33,6 \\
& $\geq 31$ Tahun & 64 & 59,8 \\
Jumlah Anak & 1 Anak & 28 & 26,2 \\
& 2 Anak & 40 & 37,4 \\
& 3 Anak & 27 & 25,2 \\
& $>4$ Anak & 12 & 11,2 \\
Jenis Kontrasepsi & Implan & 8 & 7,5 \\
& MOW & 2 & 1,9 \\
& Pil & 29 & 27,1 \\
& Suntik & 52 & 16
\end{tabular}




\begin{tabular}{lccc}
\hline & Karakteristik Responden & $\mathbf{n}$ & \% \\
\hline \multirow{4}{*}{ Pendidikan Responden } & Tidak tamat SD & 3 & 2,8 \\
& SD & 28 & 26,2 \\
& SMP/MTs & 30 & 28,0 \\
& SMA/SMK & 38 & 35,5 \\
& Perguruan Tinggi & 8 & 7,5 \\
Pendidikan Suami & Tidak tamat SD & 22 & 1,9 \\
& SD & 29 & 27,1 \\
& SMP/MTs & 32 & 29,9 \\
Biaya Untuk KB & SMA/SMK & 41 & 38,3 \\
& Perguruan Tinggi & 3 & 2,8 \\
BPJS & Gratis & 40 & 37,4 \\
& Sendiri & 67 & 62,6 \\
& Tidak ada & 28 & 26,2 \\
& PBI & 53 & 49,5 \\
& Mandiri & 26 & 24,3 \\
\hline
\end{tabular}

Sumber Data : Primer, 2019

Berdasarkan tabel 1 diatas menunjukan berpendidikan SMA/SMK sebanyak 38,3\% . bahwa dari 107 responden sebagian besar berumur $\geq$ Sementara itu responden memilih biaya untuk KB 31 Tahun 59,8\%, memiliki 2 anak 37,4\% , secara pribadi atau sendiri sebanyak 62,6\% berdasarkan jenis alat kontrasepsi yang paling sedangkan pada tabel diatas menunjukan bahwa banyak digunakan oleh responden yaitu suntik responden dominan memiliki kartu BPJS PBI sebanayak 48,6\% , responden berpendidikan sebanyak 49,5\%.

SMA/SMK $35,5 \%$ demikian juga suami

\section{a. Distribusi Responden Berdasarkan Variabel Pengetahuan}

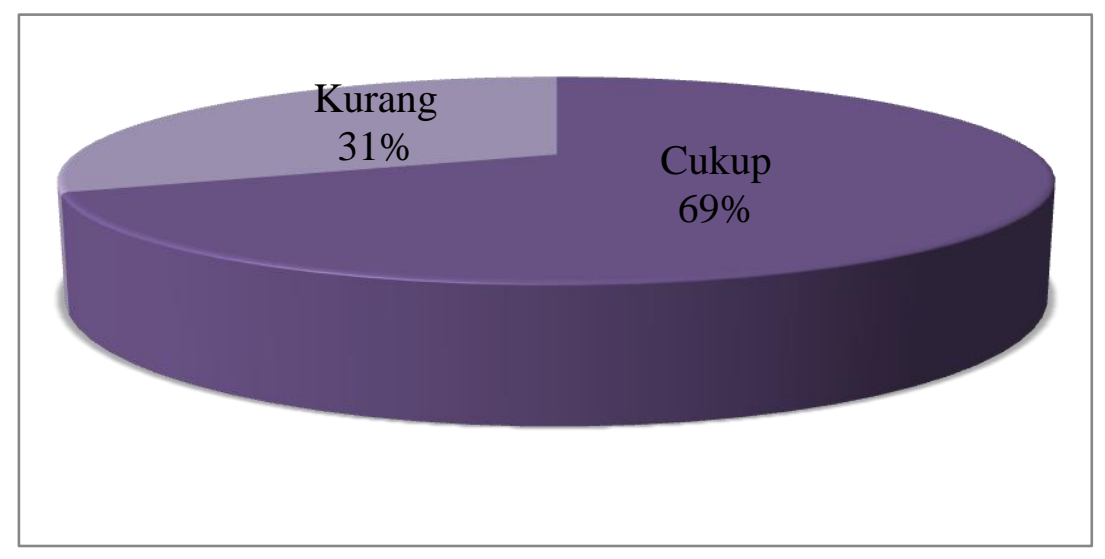

Gambar 1. Distribusi Pengetahuan Kontrasepsi IUD di Kelurahan Sidodadi

Berdasarkan gambar 1. diatas dapat diketahui

bahwa sebagian besar responden memiliki

pengetahuan cukup tentang IUD yaitu sebanyak 74

atau (69\%) responden, sedangkan responden

berpengetahuan kurang 33 atau (31\%). 


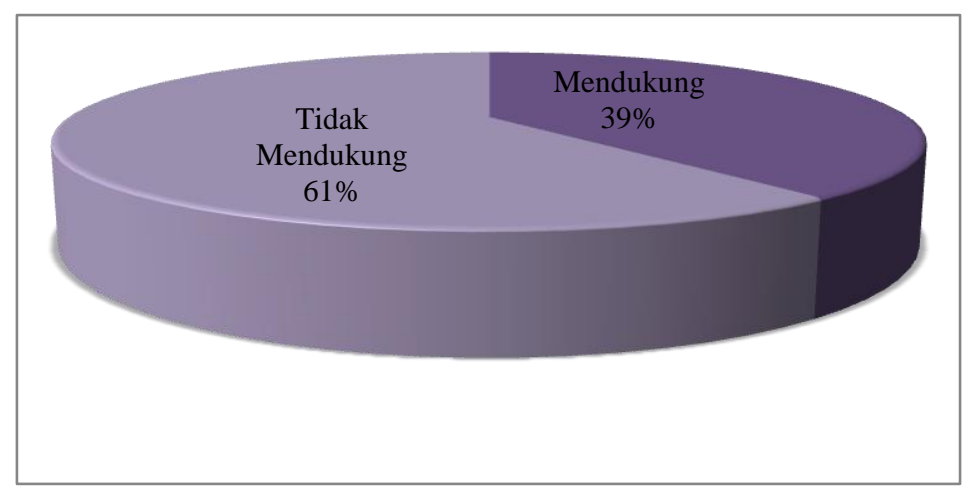

Gambar 2. Distribusi Dukungan Suami Dengan Minat Ibu Dalam Pemilihan Alat Kontrasepsi IUD di Kelurahan Sidodadi

Berdasarkan gambar 2. diatas menunjukan sedangkan sisanya 42 atau (39\%) responden bahwa 65 atau (61\%) suami tidak mendukung mendapat dukungan dari suami untuk memilih alat terhadap pemilihan alat kontrasepsi IUD untuk istri, kontrasepsi IUD.

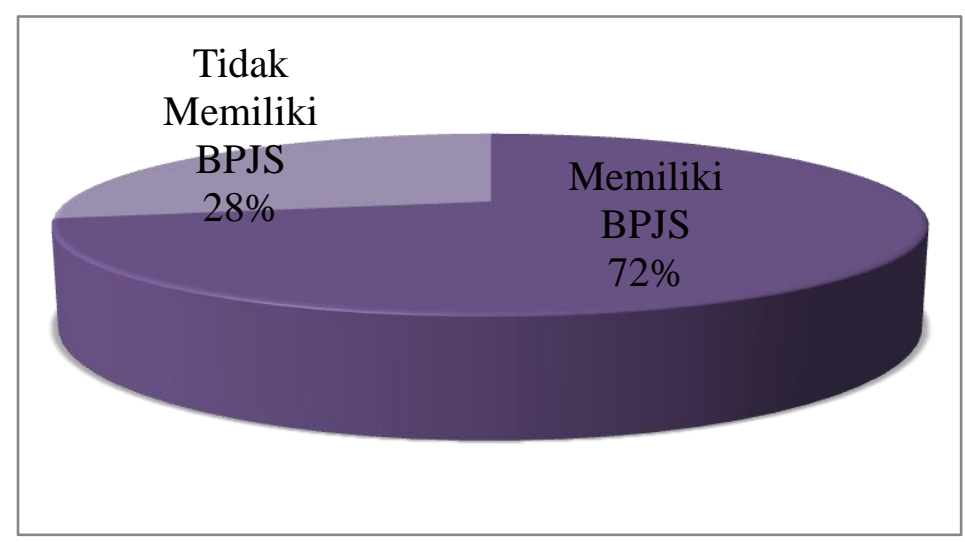

Gambar 3. Distribusi Kepemilikan BPJS Dengan Minat Ibu Dalam Pemilihan Alat Kontrasepsi IUD di Kelurahan Sidodadi

Berdasarkan gambar 3. diatas dapat hanya 30 atau $(28,0 \%)$ responden yang tidak diketahui bahwa sebagian besar responden memiliki memiliki kartu BPJS.

kartu BPJS yaitu sebanyak 77 atau $(72,0 \%)$, dan

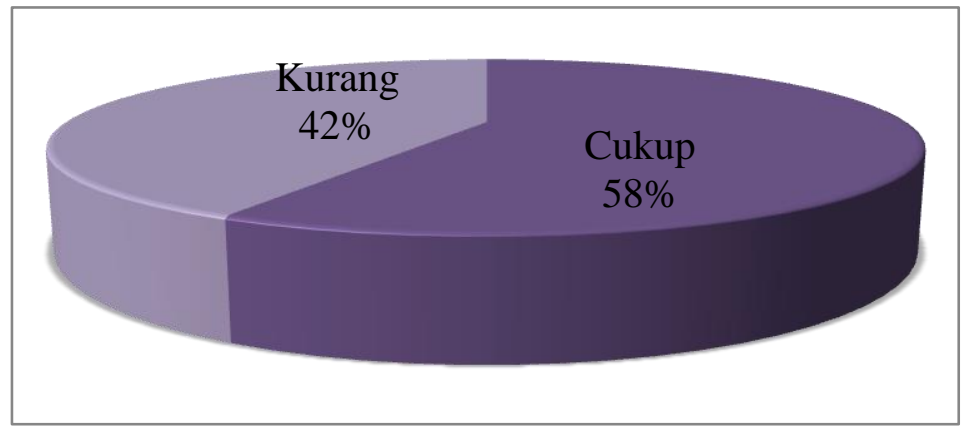

Gambar 4. Distribusi Berdasarkan Media Informasi Dengan Minat Ibu Dalam Pemilihan Alat Kontrasepsi IUD di Kelurahan Sidodadi 
Berdasarkan gambar 4. diatas dapat diketahui bahwa sebagian besar responden mendapatkan akses media informasi yang kurang yaitu sebanyak
30 atau $(61,7 \%)$. Hanya 41 atau $(38,3 \%)$ responden yang cukup mendapatkan akses media informasi mengenai IUD.

\section{Hasil Analisis Bivariat}

Faktor-faktor yang berhubungan dengan kurangnya minat ibu dalam pemilihan kontrasepsi IUD

Tabel 2. Hubungan Antara Pengetahuan, Dukungan suami, BPJS dan Media Dengan Minat Ibu Dalam Pemilihan Alat Kontrasepsi IUD di Kelurahan Sidodadi Kecamatan Wonomulyo

\begin{tabular}{|c|c|c|c|c|c|c|c|}
\hline \multirow{3}{*}{ Variabel } & \multicolumn{4}{|c|}{ Minat Dalam Pemilihan IUD } & \multirow{2}{*}{\multicolumn{2}{|c|}{ Total }} & \multirow{3}{*}{$P$-Value } \\
\hline & \multicolumn{2}{|c|}{ Tdk Berminat } & \multicolumn{2}{|c|}{ Berminat } & & & \\
\hline & $\mathrm{n}$ & $\%$ & $\mathrm{n}$ & $\%$ & $\mathrm{n}$ & $\%$ & \\
\hline Pengetahuan & & & & & & & 0,149 \\
\hline Cukup & 56 & 75,7 & 18 & 24,3 & 74 & 100 & \\
\hline Kurang & 29 & 87,9 & 4 & 12,1 & 33 & 100 & \\
\hline Dukungan Suami & & & & & & & 0,009 \\
\hline Mendukung & 28 & 66,7 & 14 & 33,3 & 42 & 100 & \\
\hline Tidak Mendukung & 57 & 87,7 & 8 & 12,3 & 65 & 100 & \\
\hline BPJS & & & & & & & 0,132 \\
\hline Memiliki & 64 & 83,1 & 13 & 16,9 & 77 & 100 & \\
\hline Tidak Memiliki & 21 & 70,0 & 9 & 30,0 & 30 & 100 & \\
\hline Media & & & & & & & 0,440 \\
\hline Cukup & 31 & 75,6 & 10 & 24,4 & 41 & 100 & \\
\hline Kurang & 54 & 81,8 & 12 & 18,2 & 66 & 100 & \\
\hline
\end{tabular}

Sumber Data : Primer , 2019

Berdasarkan Tabel 2. diatas diketahui bahwa faktor-faktor yang berhubungan secara signifikan dengan minat ibu dalam pemilihan alat kontrasepsi IUD adalah dukungan suami . sedangkan pengetahuan, kepemilikan BPJS dan media informasi tidak berhubungan signifikan dengan minat ibu dalam pemilihan alat kontrasepsi IUD pada masyarakat di Kelurahan Sidodadi Kecamatan Wonomulyo.

\section{PEMBAHASAN}

\section{Hubungan Pengetahuan Responden Dengan} Minat Ibu Dalam Pemilihan Alat Kontrasepsi IUD.

Berdsasarkan hasil penelitian, dari hasil uji statistik dengan menggunakan Uji Chi-Square maka di peroleh nilai $\rho>\alpha$ dengan demikian Ho diterima sehingga dapat disimpulkan bahwa tidak terdapat hubungan yang signifikan antara pengetahuan dengan minat dalam pemilihan alat kontrasepsi IUD pada masyarakat di Kelurahan Sidodadi Kecamatan Wonomulyo.

Hal tersebut dapat disebabkan karena mayoritas responden memiliki pengetahuan yang cukup. Walaupun seseorang telah mengetahui berbagai hal mengenai jenis alat kontrasepsi baik sisi positif maupun sisi negatifnya, akan tetapi kebanyakan juga mereka sebelum memilih alat kontrasepsi terlebih dahulu melakukan konseling kepada Bidan/Tenaga Kesehatan seperti Puskesmas, Pustu dan RS untuk mendapatkan 
nasehat dan petunjuk mengenai jenis alat kontrasepsi mana yang paling cocok bagi dirinya dan memutuskan alat kontrasepsi apa yang dipercayainya. Sehingga pengetahuan tidak mempunyai hubungan dengan pemilihan alat kontrasepsi IUD karena orang yang berpengetahuan cukup sebanding dengan orang yang berpengetahuan kurang dengan kata lain tidak ada kecendrungan pengetahuan dalam memilih alat kontrasepsi IUD. Pengetahuan merupakan salah satu faktor yang mempengaruhi perilaku,sikap dan tindakan manusia. Pengetahuan masyarakat, dalam hal ini responden terhadap KB akan mempengaruhi perilaku, sikap dan tindakan masyarakat terhadap $\mathrm{KB}$, baik dalam hal pemilihan alat kontrasepsi maupun kesadaran untuk melakukan KB.

Menurut Soekidjo Notoadmojo dalam pembentukan sikap sangat dipengaruhi oleh factor prngetahuan. Adanya pengetahuan akan mempengaruhi persepsi seseorang sehingga orang mempunyai sikap dan kemudian bias terlihat dalam perbuatannya. Peranan pengetahuan dalam ber-KB diarahkan pada pemahaman PUS tentang umur yang sehat untuk hamil dan melahirkan , jarak kehamilan yang terlalu berisiko, serta jumlah anak yang ideal guna mencapai keluarga bahagia dan sejahtera.

Untuk mencapai norma keluarga kecil bahagia dan sejahtera perlu pengetahuan tentang kontrasepsi, manfaat, peranan, dan resiko-resiko yang ditemukan pada peserta keluarga berencana. Bila pengetahuan ini sudah dihayati, maksimal untuk melaksanakan keluarga berencana, penggunaan kontrasepsi apapun dapat diterima karena apapun kontrasepsi yang digunakan secara baik berkelanjutan adalah jauh lebih aman dari pada tidak menggunakan sama sekali.

Minat merupakan salah satu gejala psikologis yang bersifat positif, karena minat diawali dengan perasaan tertarik pada suatu stimulus tertentu. Selain itu minat dikatakan lebih bersifat aktif dari pada pasif yaitu bahwa minat dapat mendorong individu untuk bergerak mendekati sesuatu yang diminatinya (Amonimous, 2009).

Hasil penelitian ini sejalan dengan penelitian yang dilakukan oleh Dewi Fatimah pada tahun 2013 dengan judul Faktor-faktor yang berhubungan dengan pemilihan alat kontrasepsi dalam rahim (AKDR) di wilayah kerja Puskesmas Kecamatan Pasar Rebo yang mengatakan bahwa ada hubungan yang signifikan antara pengetahuan dengan pemilihan AKDR dengan nilai $\rho>0,05$. (Studi et al. 2013). Peneliti mengatakan bahwa hal tersebut dapat disebabkan karena mayoritas responden memiliki Pengetahuan yang baik dan tingkat pendidikan yang tinggi.

Pengetahuan dapat diperoleh melalui pendidikan, baik pendidikan formal maupun informal. Selain itu pengetahuan dapat diperoleh dari pengetahuan orang lain dengan melihat, mendengar atau menilai alat-alat komunikasi seperti radio, buku, majalah, dan lain-lain.(Pitriana 2011).

Pengetahuan juga dipengaruhi oleh pengalaman seseorang faktor-faktor luar orang tersebut (lingkungan), baik fisik maupun non fisik dan sosial budaya yang kemudian pengalaman tersebut diketahui, diapresiasikan, diyakini sehingga menimbulkan motivasi serta niat untuk 
bertindak dan akhirnya terjadi perwujudan niat berbentuk perilaku (Annisa, 2011).

Hal ini tidak sejalan dengan penelitian yang dilakukan oleh Eminur Itri Sari pada tahun 2016 dengan judul faktor-faktor yang berhubungan dengan rendahnya minat ibu terhadap penggunaan metode kontrasepsi jangka panjang di BPS Sri Romdhati Semin Gunungkidul yang mengatakan bahwa Pengetahuan ibu tentang MKJP berhubungan dengan minat MKJP. Peneliti mengatakan bahwa Pengetahuan menjadi dasar dalam berperilaku dan mempersepsikan sesuatu. Pengetahuan yang benar akan mempertinggi minat penggunaan MKJP.

Pengetahuan seseorang dapat dipengaruhi beberapa faktor diantarnya pendidikan, pengalaman, paparan media massa, ekonomi dan hubungan sosial. Tingkat pendidikan yang tinggi dapat memungkinkan seseorang dengan mudah memperoleh informasi yang didapat dari berbagai sumber media, seperti media cetak, media elektronik dan media massa (Notoatmodjo, 2003).

Berdasarkan penelitian ini distribusi umur responden yang mayoritas berumur 21-31 tahun dan memiliki jumlah anak 2 terbanyak. Ibu yang telah memiliki 2 anak atau lebih cenderung berminat menggunakan MKJP karena ibu mulai berpikir untuk berhenti memiliki anak terlebih lagi jika ibu telah berada pada usia tidak produktif karena ibu mulai memikirkan resiko persalinan (BKKBN, 2010).

\section{Hubungan Dukungan Suami Dengan Minat Ibu} Dalam Pemilihan Alat Kontrasepsi IUD.

Berdasarkan hasil penelitian, dari hasil uji statistik dengan menggunakan Uji Chi-Square maka diperoleh nilai $\rho<\alpha$ Dengan demikian Ha diterima dan Ho ditolak sehingga dapat disimpulkan bahwa terdapat hubungan yang signifikan antara dukungan suami dengan minat ibu dalam pemilihan alat kontrasepsi IUD pada masyarakat di Kelurahan Sidodadi Kecamatan Wonomulyo.

Hal ini disebabkan dukungan instrumental yang diberikan suami kepada istri kurang, responden mengungkapkan tidak didampingi oleh suami saat konsultasi dengan bidan tentang alat kontrasepsi IUD, maka suami kurang mendapatkan informasi tentang IUD sebab kurangnya informasi yang diperoleh suami tidak mengetahui bahwa IUD merupakan alat kontrasepsi yang mempunyai efektifitas tinggi serta tidak dapat meyakinkan pada istri. Dukungan emosi yang diberikan suami pada istri cenderung tidak ada sebab responden mengatakan bahwa tidak setuju jika istri menggunakan IUD.

Berdasarkan distribusi frekuensi pendidikan suami mayoritas SMA/SMK, pada umumnya semakin tinggi pendidikan seseorang semakin baik pula pengetahuannya, bertambahnya umur seseorang dapat pula berpengaruh pada pengetahuan yang diperolehnya, sumber pengetahuan berasal dari pengindraan indra penglihatan, penglihatan, pendengaran, penciuman, rasa dan raba (Wijayanti, 2009). Faktor lain adalah teknologi semakin majunya teknologi dan membaiknya sarana komunikasi mengakibatkan membanjirnya arus informasi dari luar yang sulit diseleksi.

Menurut Friedman (2008) faktor-faktor yang mempengaruhi dukungan termasuk didalamya adalah pendidikan dan tingkat pengetahuan Keyakinan seseorang terhadap 
adanya dukungan terbentuk oleh variabel intelektual yang terdiri dari pengetahuan, latar belakang pendidikan dan pengalaman masa lalu. Kemampuan untuk memahami faktor-faktor yang berhubungan dengan penyakit menggunakan pengetahuan tentang kesehatan untuk menjaga kesehatan dirinya.

Cara bagaimana keluarga memberikan dukungan, biasanya mempengaruhi penderita dalam melakukan kesehatan misalnya : klien juga kemungkinan besar akan melakukan tindakan pencegahan jika keluarganya melakukan halsama. Misal : anak yang selalu di ajak melakukan pemeriksaan kesehatan rutin, maka ketika punya anak nanti dia akan melakukan hal yang sama.

Hasil penelitian ini juga sejalan dengan penelitian yang dilakukan oleh Bernadus, dkk.2013 dengan judul faktor-faktor yang berhubungan dengan pemilihan alat kontrasepsi AKDR bagi akseptor KB di Puskesmas Jailolo, yang menjelaskan bahwa berdasarkan hasil uji statistik Uji Chi Square nilai $\rho<\alpha$ maka dapat disimpulkan bahwa ada hubungan persetujuan pasangan dengan pemilihan AKDR di Puskesmas Mandalle Kab Pangkep. Pada penelitian ini mengatakan bahwa responden dengan persetujuan pasangan yang mendukung lebih berpeluang dalam memilih AKDR dari pada pasangan yang tidak mendukung. Ambarwati juga mengemukakan bahwa persetujuan pasangan/suami berperan penting dalam pemilihan AKDR. Pemasangan AKDR membutuhkan kerjasama dengan suami karena alasan takut benangnya mengganggu saat bersenggama, Dukungan suami sangat diperlukan untuk pengambilan keputusan dalam ber KB karena kenyataan yang terjadi dimasyarakat bahwa apabila suami tidak mengijinkan atau tidak mendukung hanya sedikit ibu yang berani untuk tetap memasang alat kontrasepsi tersebut. Dukungan suami sangat penting untuk memotivasi dan mensupport istri dalam pemilihan alat kontrasepsi yang akan digunakan. Tidak adanya dukungan dari suami seringkali membuat istri tidak berhak memutuskan sesuatu dalam mengambil keputusan. Dukungan yang dapat diberikan antara lain memilih kontrasepsi yang cocok, yaitu kontrasepsi yang sesuai dengan, kondisi istrinya, mengingatkannya untuk control dan mengantarkannya ketika ada efek samping atau komplikasi.

Hasil penelitian ini sesuai dengan teori (WHO) yang menyatakan bahwa hubungan seorang wanita dengan pasangannya dapat menjadi faktor dalam menentukan pemilihan kontrasepsi tertentu. Karena pada banyak masyarakat, pasangan tidak saling berkomunikasi mengenai keluarga berencana, pihak wanitalah yang sering kali harus memperoleh dan menggunakan alat kontrasepsi bila ingin mengontrol kesuburannya

Hubungan Kepemilikan BPJS Dengan Minat Ibu Dalam Pemilihan Alat Kontrasepsi IUD.

Berdsasarkan hasil penelitian, Uji ChiSquare maka diperoleh nilai $\rho>\alpha$. Dengan demikian dapat disimpulkan bahwa tidak terdapat hubungan yang signifikan antara kepemilikan BPJS dengan minat ibu dalam pemilihan alat kontrasepsi IUD.

Hal ini disebabkan pelayanan oleh bidan paling diminati wanita untuk mendapatkan pelayanan KB. Walaupun telah memiliki kartu 
BPJS, pada umumnya wanita rela membayar sendiri untuk mendapatkan pelayanan $\mathrm{KB}$ di bidan praktek mandiri. Berdasrkan distribusi frekuensi jenis BPJS responden lebih banyak memiliki kartu BPJS PBI yang gratis ditanggung oleh Pemerintah selain dari itu responden mengungkapkan bahwa Keluhan yang sering dihadapi wanita dalam menggunakan kartu BPJS antara lain adalah lama waktu menunggu, dan kartu ini hanya dapat digunakan pada faskes tertentu, jenis pelayanan terbatas, jenis obat terbatas dan kurang berkualitas, ribet dan berbelit-belit, serta masyarakat miskin dengan PBI sering diabaikan menjadi alasan sebagian masyarakat.

Penelitian ini sejalan dengan penelitian yang dilakukan oleh Hadriah Oesman pada tahun 2017 yang berjudul pola pemakaian kontrasepsi dan pemanfaatan kartu Badan Penyelengara Jaminan Sosial (BPJS) kesehatan dalam pelayanan keluarga berencana di indonesia, yang menjelaskan bahwa berdasarkan hasil uji statistik Uji Square nilai $\rho<\alpha$ maka dapat disimpulkan bahwa Pemakaian kartu BPJS Kesehatan untuk pelayanan $\mathrm{KB}$ memiliki hubungan yang bermakna terhadap pemakaian MKJP.

Studi ini mengungkapkan bahwa pada pola pemakaian kontrasepsi dan tempat pelayanan/faskes yang digunakan untuk mendapatkan pelayanan $\mathrm{KB}$ di era JKN dibandingkan kondisi sebelum JKN. Dilihat menurut metode $\mathrm{KB}$ yang digunakan, suntikan $\mathrm{KB}$ tetap merupakan yang tertinggi, berikutnya adalah pil, kemudian implant dan IUD. Banyaknya peraturan tentang JKN yang diterbitkan menimbulkan pemahaman yang berbeda-beda bagi pengelola di lapangan, provider, termasuk bidan dan masyarakat dalam memaknainya.(Oesman 2017) Pemakaian kontrasepsi non MKJP masih tinggi. Pemanfaatan kartu BPJS kesehatan untuk pelayanan KB masih rendah, padahal pemanfaatan kartu BPJS kesehatan berpeluang hampir empat kali dapat mendorong pemakaian KB MKJP.

Penelitian ini tidak sejalan dengan penelitian yang dilakukan oleh Sindhy Desitavani 2017 berjudul faktor-faktor yang berhubungan dengan pemilihan alat kontrasepsi intra uterine devices (IUD) pada ibu di kecamatan bantul yogyakarta, yang menjelaskan bahwa responden berdasarkan dukungan suami di kecamatan Bantul Yogyakarta, adalah mayoritas ibu mendapatkan dukungan suami dalam kategori cukup, dalam penelitian ini juga mengatakan bahwa akseptor yang memilih IUD dan mendapatkan dukungan suami dengan kategori baik karena suami dilibatkan dalam pemilihan alat kontrasepsi dan suami lebih berperan dalam menentukan alat kontrasepsi untuk istrinya. IUD lebih dianjurkan kepada pasangan suami istri yang ingin menunda kehamilan dan aman jika digunakan dalam jangka panjang.

Penggunaan kartu BPJS kesehatan oleh wanita untuk mendapatkan pelayanan KB masih rendah disebabkan karena selama ini masyarakat banyak yang beranggapan bahwa kartu BPJS hanya digunakan untuk berobat dan tidak dapat untuk pelayanan KB. Dari hasil analisis karakteristik reponden jenis kontrasepsi suntik yang paling banyak digunakan oleh masyarakat Sidodadi, Pelayanan Keluarga Berencana (KB) merupakan salah satu manfaat pelayanan promotif dan preventif. Pasal 21 Peraturan Presiden (PP) No. 19 tahun 2016 disebutkan bahwa pelayanan 
KB meliputi konseling, pelayanan kontrasepsi termasuk vasektomi dan tubektomi.

\section{Hubungan Media Informasi Dengan Minat Ibu} Dalam Pemilihan Alat Kontrasepsi IUD.

Berdsasarkan hasil penelitian, Uji ChiSquare maka diperoleh peroleh nilai $\rho>\alpha$ dengan demikian disimpulkan bahwa tidak terdapat hubungan yang signifikan antara media informasi dengan minat ibu dalam pemilihan alat kontrasepsi IUD. Hal ini dikarenakan beberapa faktor bahwa sikap responden dipengaruhi oleh pengalaman pribadi, pengaruh orang lain yang dianggap penting bagi individu seperti: suami, orang tua dan keluarga.

Hasil penelitian ini tidak sejalan dengan hasil penelitian Eminur Itri Sari pada tahun 2016 yang berjudul faktor-faktor yang berhubungan dengan rendahnya minat ibu terhadap penggunaan metode kontrasepsi jangka panjang di bps sri romdhati semin gunungkidul, yang menjelaskan bahwa berdasarkan hasil uji statistik Uji ChiSquare nilai $\rho<\alpha$ maka dapat disimpulkan Paparan sumber informasi tentang MKJP berhubungan dengan minat MKJP. Studi ini mengatakan bahwa ibu diperkotaan memiliki cenderung menggunakan MKJP yang lebih tinggi dibandingkan ibu di pedesaan karena ibu di perkotaan lebih banyak terpapar informasi mengenai MKJP dari berbagai sumber. (Sari 2016)

Dari hasil penelitian ini pengetahuan tidak berpengaruh terhadap minat ibu sedangkan faktor dukungan suami berpengaruh terhadap minat ibu, berdasarkan hasil penelitian responden yang cukup mengakses media informasi sedikit yang berminat dikarenakan persepsi negatif responden setelah mengakses media mereka beranggapan bahwa ada efek samping dan komplikas dari IUD yang berbahaya responden cenderung melihan hal negatif IUD ketimbang positifnya.

Secara umum media merupakan sarana penyampaian informasi dari sumber informasi (komunikator) kepada penerima informasi (komunikan). Masuknya informasi oleh media membawa dampak perubahan sosial dalam kehidupan masyarakat.Informasi yang sampai kemasyarakat dapat ditanggapi berbeda-beda oleh setiap individu tergantung pada kepentingannya masing-masing serta tergatung dari kemampuan masyarakat dalam memanfaatkan informasi yang datang secara proporsional.Informasi-informasi yang diterima dari media tersebut mempengaruhi kehidupan sosial budaya suatu masyarakat baik dalam persepsi sikap serta perilaku hidupnya (Wawan, 2010).

Responden yang memiliki persepsi IUD positif cenderung berminat untuk menggunakan IUD persepsinya mencakup keamanan serta keuntungan dan kerugian penggunaan sedangkan responden yang memiliki persepsi negatif dengan menganggap IUD mengancam kesehatan mereka serta lebih banyak merugikan, responden tentunya tidak berminat untuk menggunakan alat kontrasepsi IUD.

\section{KESIMPULAN}

Faktor yang berhubungan dengan minat ibu dalam pemilihan alat kontrasepsi IUD di Kelurahan Sidodadi Kecamatan Wonomulyo adalah dukungan suami $(\mathrm{p}=0,009)$, sedangkan faktor-faktor yang tidak berhubungan dengan minat ibu dalam pemilihan alat kontrasepsi IUD adalah pengetahuan, BPJS dan media. Untuk 
pengetahuan menunjukan $(\mathrm{p}=0,149), \quad$ BPJS menunjukan $(p=0,132)$ dan paparan media informasi menunjukan $(\mathrm{p}=0,440)$. Responden disarankan untuk berkonsultasi lebih lanjut mengenai kebenaran dari mitos-mitos IUD dengan bidan untuk lebih menambah pemahaman dan persepsi positif IUD

\section{SARAN}

Diharapkan Bidan untuk memberikan sosialisasi terutama terkait layanan IUD dengan BPJS, mitos-mitos, efektivitas dan efek samping IUD dan melibatkan suami dalam sosialisasi agar suami dapat mendukung istrinya untuk menggunakan IUD, selain itu setiap Kepala Lingkungan Sidodadi diharapkan dapat bekerjasama dengan tenaga kesehatan atau Puskesmas pentingnya penyuluhan mengenai pentingnya kontrasepsi untuk menerapkan program keluarga berencana yang sesuai kepada setiap individu serta membentuk Kader KB disetiap lingkungannya.

\section{UCAPAN TERIMA KASIH}

Terima kasih kepada kedua orang tua dan keluarga yang memberikan seluruh bantuan dan dukungan dalam menyelesaikan penelitian ini dan kepada Fakultas Kesehatan Masyarakat Universitas Al Asyariah Mandar, Kepala Dinas Penanaman Modal dan PTSP, Camat Wonomulyo, serta Lurah Sidodadi yang telah memberikan izi untuk penelitian ini.

\section{DAFTAR PUSTAKA}

Handayani, Sri (2010) Buku Ajar Pelayanan
Kesehatan
Berencana. Yogyakarta: Pustaka
Rihama.

William, S. and Surabaya, B. (2017) 'Menggunakan Kontrasepsi Iud Di Bps Mien Hendro'. Jurnal Kebidanan, Vol. 6 no. $1 \mathrm{hlm}$. 1-69

Badan Kependudukan dan Keluarga Berencana Nasional, BKKBN; 2015 Depkes RI Polewali

Bernadus, Johana. D, 2013. Faktor-Faktor Yang Berhubungan Dengan Pemilihan Alat Kontrasepsi Dalam Rahim (Akdr) Bagi Akseptor Kb Di Puskesmas Jailolo.Jurnal Ilmiah Keperawatan (online), Vol. 1, No. 1 hlm. 1-10, Diakses 18 Desember 2018.

Handayani, Desy, 2010. Faktor-faktor yang Mempengaruhi Ibu dalam Pengambilan Keputusan Memilih Alat Kontrasepsi dalam Rahi (AKDR) di Wilayah Bidan Praktik Swasta Titik Sri Suparti Boyolali. Jurnal KESMADASKA (online),Vol.1,No.1hlm.1-85, Diakses 18 Desember 2018.

Hartanto, Hanafi, 2004, Keluarga Berncana Dan Kontrasepsi (Cet. 5) Jakarta :Pustaka Sinar Harapan

FKM, 2018. Buku Panduan Penulisan Skripsi. FKM UNASMAN. Polewali Mandar

Notoatmodjo, Soekidjo. 2005. Metode Penelitian Kesehatan. PT. Rineka Cipta. Jakarta

Sugiyono, 2018. Metode Penelitian manajemen. Alfabeta. Bandung

Hartik, Andi. 2016. "Laju Pertumbuhan Penduduk." Malang.

Bkkbn.Laju.Pertumbuhan.Penduduk.4.Juta .Per.Tahun.Idealnya.2.Juta.

Badan Penelitian Dan Pengembangan Kesehatan. 2013. "Riset Kesehatan Dasar (RISKESDAS) 2013." Laporan Nasional 2013: 1-384. Hasil Riskesdas 2013.

BPJS Kesehatan. 2016. "BPJS Kesehatan.” Badan Penyelenggara Jaminan Sosial Kesehatan: Https://Bpjs-Kesehatan.Go.Id/Bpjs/. Https://Bpjs-Kesehatan.Go.Id/Bpjs/.

Handayani, Desy. 2010. "Faktor-Faktor Yang Mempengaruhi Ibu Dalam Pengambilan Keputusan Memilih Alat Kontrasepsi." Jurnal Kesmadaska 1(1): 56-65.

Suryani, Dwi (2010). "Hubungan Dukungan Suami..., Fakultas Ilmu Kesehatan UMP, 2014." (2007): 18-37.

PRASTIANI, A'AS (2009). "Hubungan Pemakaian Kontrasepsi..., Fakultas Ilmu Kesehatan UMP, 2014.” (2002).

Kemenkes RI. 2014. "Situasi Dan Analisis 
Keluarga Berencana.” Kementerian

Kesehatan Republik Indonesia:

Kesehatan, Potiteknik, And K E M Enkes. 2005. “: 1. 2.": 9-22.

Maulana Et Al. 2015. "Hubungan Dukungan

Suami Dengan Pemakaian Alat

Kontrasepsi IUD.” Kebidanan: 13-54.

Oesman, Hadriah. 2017. "Pola Pemakaian

Kontrasepsi Dan Pemanfaatan Kartu Badan Penyelengara Jaminan Sosial ( Bpjs ) Kesehatan Dalam Pelayanan Keluarga Berencana Di Indonesia The Pattern Of Contraceptive Use And Utilization Of BPJS-Health Card On Family Planning Services In Indon." Jurnal Kesehatan Reproduksi 8(1): 15-29. Hadriah.Oesman@Gmail.Com.

Pitriana. 2011. "Faktor Yang Berhubungan Dengan Pemilihan Kontrasepsi Suntik." UNASMAN.

Sari, Eminur Itri. 2016. "Faktor-Faktor Yang Berhubungan Dengan Rendahnya Minat Ibu Terhadap Penggunaan Metode Kontrasepsi Jangka Panjang Di BPS Sri Romdhati Semin Gunung Kidul.” Naskah Publikasi Universitas 'Aisyiyahyogyakarta.

Studi, Program Et Al. 2013. "Faktor-Faktor Yang Berhubungan Dengan Penggunaan Alat Kotrasepsi Dalam Rahim (Akdr) Di Wilayah Kerja Puskesmas Kecamatan Pasar Rebo Jakarta Timur."

Salisbury, P. (2016). Family Planning Knowledge,Attitudes Practices In Refugee And Migrant Pregnant And PostPartum Women On The Thailand Myanmar. Reproductive Health, 2-13. 